\title{
Global challenges, local impact
}

\section{Ilse Schröder ${ }^{1}$, Ed de Jonge ${ }^{2}$, Erik Mooij ${ }^{3}$, Frank Evers ${ }^{4}$}

${ }^{1}$ Archimedes Institute for Education, HU University of Applied Sciences Utrecht, The Netherlands ${ }^{2}$ Institute for Social Work, HU University of Applied Sciences Utrecht, The

Netherlands, ${ }^{3}$ Institute for Media, HU University of Applied Sciences Utrecht, The Netherlands, ${ }^{4}$ Perfect Storm, The Netherlands

\begin{abstract}
In 2015, the UN set 17 global goals, the so-called Sustainable Development Goals (SDGs) for the year 2030, "a universal call to action to end poverty, protect the planet and ensure that all people enjoy peace and prosperity". Although these challenges are global, their impact manifests itself on a local level.

An inspiring challenge for HU UAS Utrecht is to educate self-confident (upcoming) professionals who contribute to the realization of these global goals by creating local impact. In our opinion such professionals are socially involved, cope with complexity, think systemic and work trans-disciplinary. Furthermore, they 'mix and match' personal, societal and professional development, which will not be confined to formal education but lasts a lifetime.
\end{abstract}

This complex challenge forges us to transform our thinking about education and how to organize learning, and about how, where and with whom we educate. UAS's will have to cooperate with private, public and research partners and create communities in which all participants work, learn and develop themselves while facing new challenges.

Keywords: SDG; social impact; personal development;complexity; challenge based learning 


\section{Introduction}

HU UAS Utrecht (HU) aspires to contribute to an open, just and sustainable society and has committed itself to the Sustainable Development Goals of the United Nations (UN, 2015) while focusing on the quality of living (together) in an urban environment. Quite recently HU has stated her ambitions for 2026 (HU, 2019), emphasizing it's role in solving complex (mission driven) challenges. HU will take the lead in cocreating local impact concerning complex and transdisciplinary global challenges.

The labor market increasingly demands Jacks of all trades, professionals who are critical, inquisitive, innovative, entrepreneurial, and cooperative with an inclusive and international orientation. Future education encompasses development as a professional as well as a person and a citizen, able to tackle society's complex challenges.

\section{The need for local impact and the role of UAS's}

At present, most of higher education is discipline- or domain oriented. Complex societal challenges however encompas a multitude of interconnected aspects touching upon several domains and therefore require an integrated approach of diverse perspectives, for instance environmental, economical, technical, social and juridical. In such cases a multidisciplinary approach will not suffice; an interdisciplinary or even a transdisciplinary approach is required.

In a transdisciplinary approach, different disciplines, meanings and aspects are involved on the basis of equality in initiating, designing and creating sustainable solutions for complex challenges. In fact, the different disciplines need each other for a broader view on the issue and the emergence of crossovers to new ideas. Transdisciplinarity means extending the cooperation. To create impact, not only scientists but also other social actors are involved in the process, like users, clients, special interest groups. The primacy of knowledge and solutions is no longer solely with the expertsand co-design and co-creation are required.

Transdisciplinarity increases the chance that the results will actually be used. Without interaction with all stakeholders, without co-design and co-creation, it is pie in the sky and it provides too often only reports and papers. (Bunders and Regeer, 2009).

Thompson Klein expresses transdisciplinarity as follows:

“Transdisciplinarity transcends disciplinary worldviews through 
1. More comprehensive frameworks and/ or

2. problem-oriented research that crosses boundaries of academic disciplines and the public and private spheres.

Major examples of the first connotation-new synthetic frameworks-include general systems theory, sustainability and new, broader paradigms for health and wellness.

In the second connotation, mutual learning, joint work, and knowledge integration are key to solving "real-world" problems." (Thompson Klein, 2014)

Transdisciplinarity does not arise automatically. Cross-discipline and cross-domain frameworks, concepts and collaboration are available but will futher have to be developed. Social questions to generate impact on complex challenges are becoming increasingly evident. So, while working on SDG's and complex challenges derived from them, frameworks, concepts, models, methods and cooperation have to be developed together with all stakeholders. This implies that education, applying other (new) didactics, is moving more and more from campus to practice and is pre-eminently a task for UAS's.

UAS's have are in a unique position to contribute to solving these issues with their applied approach to research and their strong ties to the (professional) community. Yet two important and inspiring challenges for $\mathrm{HU}$ result from this. The first challenge is how to educate transdisciplinary working (upcoming) professionals who contribute to the society's challenges and make local impact. The second challenge is to transform our thinking about education and how to organize learning.

We shall discuss both.

\section{Impact makers: a whole-person approach to education}

To cope with the first challenge, to educate transdisciplinary working (upcoming) professionals who contribute to the Sustainable Development Goals and make local impact, UAS's have to reach beyond disciplines and work across boundaries in guiding and coaching transdisciplinary innovation professionals.

Enninga (Enninga, 2018), in her research on innovation project leaders, states that the innovation process is a non-linear process and messier than a sequence of stages. The innovation project leader has to lead during the innovation journey four intertwined processes: developing the content process, stimulating the creative process, guiding the group 
dynamics process, and managing the project constraints process. The innovation project leaders in her study experienced the biggest tension from the number of issues that were important at the same moment in time, the contradictions in and between these issues, the psychological contradictions between rational issues at one hand and emotional issues at the other, between long term and short term issues, between thinking creatively and divergently in one issue, while at the same time convergent, tight steering in another issue, the unexpected events, the differences in perspectives and the changes in perspectives from people and groups involved, under the experienced pressure of time, and over a longer time.

An inspiring challenge will be to educate such self-confident (upcoming) professionals who contribute to tackling the complex challenges in such a dynamic environment, and create local impact. In their training and in their work, these (upcoming) professionals will have to 'mix and match' personal, societal and professional development, which will not be confined to formal education but will lasts a lifetime.

Facilitating personal development can be based on the metaphor of life as a narrative biographical quest. Personal leadership is encouraged by stimulating a sense of origin, presence, belonging and destiny and by constantly facing new personal challenges. Education is enriched by elements related to for instance life orientation, spirituality, philosophy, arts, culture, sports, nature, health.

From a personal perspective, he (or she) works during the course on developing in-depth insight into his dreams, ideals, strengths, weaknesses, possibilities and impossibilities. Introspection helps him to examine them. He makes his own decisions to extend his possibilities. He tries out and evaluate (new) behavior. He deepens insight in what prevents him (inside and out) from achieving his dreams and learn to cope with that.

From a professional perspective, the (upcoming) professional will roughly delve into the specific complex social issues based on a systemic approach and the underlying disciplines. He or she is working on social challenges together with others and he takes different roles in creating impact, using insights from system theory and design-driven innovations, underlying disciplines are used.

From a societal perspective, it is about the development to active participants in society. He takes responsibility for society and his own living environment He focus on the way in which groups and people in society with different views arrive at answers and solutions. He develops his own vision on society and people and the shaping thereof in his own decisions and actions. 
Professional, personal and societal development intertwine, which makes a whole-person approach to education necessary. No two professionals are the same, every development has a personal character. Different development paths can influence each other in different ways, and thus require a very personalized learning trajectory.

\section{New partnerships for future challenges}

Transdisciplinarity and a personalized, whole-person approach to learning require a different way of organizing learning. It requires learning spaces where professionals from different disciplines, organizations and levels of expertise work and learn. These learning communities demand new partnerships and a more open organization from UAS's, where diverse stakeholders collaborate, more intensively and on an equal basis, aimed at a clear common goal.

Within these learning communities, we apply challenge based education as an open-ended approach to tackling societal issues, where

- Challenges here are local reflections of complex global challenges,

- for which a cross-domain, transdisciplinary approach is necessary,

- and where learning is mostly self-directed.

Challenging complex global challenges in an uncertain world forces us to transform our thinking about learning and its organisation. We will have to cooperate with private, public and research partners and create learning communities in which all participants work, learn and investigate, developing themselves professionally and personally while constantly facing new challenges.

\section{References}

Van Vugt, M., Hogan, R., \& Kaiser, R. B. (2008). Leadership, followership, and evolution: Some lessons from the past. American Psychologist, 63(3), 182-196. doi: 10.1037/0003066X.63.3.182.

Enninga, T (2018). Armchair Travelling the innovation journey Building a narrative repertoire of the experiences of innovation project leaders. https://doi.org/10.4233/uuid:80f3d825-cb17-4783-b43e9aa1156d847d 
Bunders, J. and Regeer, B. (2009). Knowledge Co-creation: Interaction Between Science and Society. The Hague: RMNO.

Thompson Klein, J (2014). Communication and Collaboration in Interdisciplinary Research In: Enhancing Communication \& Collaboration in Interdisciplinary Research. Book. By: Julie Thompson Klein Edited by: Michael O'Rourke, Stephen Crowley, Sanford D. Eigenbrode \& J. D. Wulfhorst 